\title{
Excess Mortality and Risk Factors for Mortality Among Patients with Severe Mental Disorders Receiving Home Care Case Management
}

\section{Wen-Yin Chen}

Taipei City Hospital

\section{Sheng-Jean Huang}

Taipei City Hospital

Chin-Kuo Chang

University of Taipei

Chun-Hung Pan

Taipei City Hospital

Sheng-Shiang Su

Taipei City Hospital

\section{Tien-Wei Yang}

Taipei City Hospital

Chian-Jue Kuo ( $\square$ tcpckuo@seed.net.tw )

Taipei City Psychiatric Center https://orcid.org/0000-0002-2773-1335

\section{Research article}

Keywords: case management, severe mental disorder, standardized mortality ratio, home care, community therapy

Posted Date: November 11th, 2019

DOI: https://doi.org/10.21203/rs.2.17145/v1

License: (a) (1) This work is licensed under a Creative Commons Attribution 4.0 International License. Read Full License

Version of Record: A version of this preprint was published at Nordic Journal of Psychiatry on August 4th, 2020. See the published version at https://doi.org/10.1080/08039488.2020.1799431. 


\section{Abstract}

Background: Home care case management (CM) is the main intervention for patients with severe mental disorders (SMDs) requiring outreach care. The present study investigated the long-term mortality outcome and associated risk factors in patients who received home care CM.

Methods: In this nationwide study, we enrolled patients who received home care CM ( $\mathrm{n}=10255)$ between January 1, 1999, and December 31, 2010; data of these patients were derived from a Taiwan health insurance database. We calculated the standardized mortality ratio (SMR) as the ratio of observed deaths in the study cohort to expected deaths in the general population and presented by diagnosis. Multivariate regression was performed to assess independent risk factors for mortality.

Results: Among 10255 patients who received home care CM, 1409 died during the study period; the overall SMR was 3.13. Specifically, patients with organic mental disorder had the highest SMR (4.98), followed by those with schizophrenia (3.89), major depression (2.98), and bipolar disorder (1.97). After adjustment for confounding factors in the multivariate analysis, patients with organic mental disorder or dementia had the highest risk of mortality, whereas the mortality risk in patients with schizophrenia was comparable to that in patients with bipolar disorder or major depression. Deceased patients had a significantly higher proportion of acute or chronic physical illnesses, including cancer, chronic hepatic disease, and pneumonia.

Conclusion: This study presented the gap of mortality in patients with SMDs receiving home care CM in Taiwan. We highlight the need for more effective strategies to improve medical care for this specified population.

\section{Strengths And Limitations Of This Study}

1. This study provides a more comprehensive picture of mortality gap in patients receiving home care case management.

2. This study highlights the need for more effective strategies to improve medical care, especially for patients with organic mental disorder.

3. Furthermore, the intervention model integrated into the health care system for physical illnesses in this specified population deserves greater attention.

4. As one of the limitations, we did not have information regarding the causes of death; therefore, we could not examine the cause or underlying disease accounting for higher mortality.

5. Another limitation is that additional studies such as a randomized clinical trial are required to investigate whether the home care case management intervention can reduce mortality.

\section{Introduction}

The burden of mental disorders has increased in recent years and is currently the major cause of lost disabilityadjusted life years globally [1]. Patients with severe mental disorders (SMDs) often present with prolonged illness with episodic exacerbations if they do not receive optimal treatment, and these patients have a high risk of premature mortality [2]. The majority of deaths in patients with SMDs occur due to preventable physical 
diseases or unnatural causes, including suicide, homicide, and accidents [3]. High mortality in patients with SMDs is a global public health challenge, particularly among those not receiving regular treatment $[4,5]$. In addition, underlying risk factors, such as economic disadvantage, negative health habits, and difficulty accessing and adhering to medical treatment, usually contribute to high mortality in patients with chronic mental illness [6].

The gap of life expectancy between patients with SMDs and the general population is usually presented as the standardized mortality ratio (SMR), which can also be considered as an index for local mental health services. Between 2004 and 2013, in a UK population, the SMR of patients with SMDs was 2.6 when different care setting cohorts were combined [7]. In addition, studies conducted in North Europe have reported that the SMR ranged from 2.2 to 3.3 between sexes in different countries [8, 9]. Meanwhile, the SMR of patients with SMDs ranged from 2.4 to 3.4 in studies conducted in East Asian countries [10, 11]. A population-based study conducted in Ethiopia reported that the overall SMR of patients with SMDs was around 2 [12]. Furthermore, several studies exploring research findings across several decades have reported that a substantial mortality gap exists between patients with schizophrenia or bipolar disorder and the general community and that the differential mortality gap has appeared to widen, rather than decrease, in recent years [13, 14]. In addition, limited studies have examined the mortality gap in other chronic mental disorders, such as organic mental disorder.

Community outreach care is an approach aimed to reduce the barriers of care for patients with SMDs and enable these patients to receive the treatment they require. In our recent study [15], we found that the CM model could effectively reduce the frequencies of psychiatric hospitalizations and involuntary admissions but had no effect on medical utilization for their comorbid physical illnesses. Recent review articles $[16,17]$ have indicated that the effectiveness of $\mathrm{CM}$ has rarely been examined using mortality indices. Therefore, the mortality outcome in patients with psychiatric disorders receiving home care $\mathrm{CM}$ warrants further evidence-based research.

In this study, we enrolled a large cohort receiving home care CM in Taiwan to follow up their long-term mortality outcome. Outcome indices, namely the SMR and incidence rate, were used with stratification of age, sex, and psychiatric diagnosis. Furthermore, potential risk factors for mortality, including demographics and physical comorbidities, were investigated.

\section{Methods}

Home care CM in Taiwan

Under the home care CM service in Taiwan, in-charge hospitals provide psychiatric treatment and basic medical care. The home care CM program of a hospital involves a multidisciplinary team including trained psychiatrists, psychiatric nurses, and social workers and related transfer service if necessary. In this program, patients undergo 1-4 face-to-face sessions per month at home for evaluating their clinical symptoms, adverse drug reactions, and social functions. In addition, service telephone numbers and a 24-hour emergency coverage provided by hospitals are available. For patients who require intensive outreach care, the program also provides mandatory community therapy. Home care CM is part of the community therapy in Taiwan [15], which is similar to the intensive CM (ICM) model, but the caseload of home care CM is higher than that of ICM. 
The Taiwan National Health Insurance Research Database (NHIRD) was used as the data source. Taiwan has introduced a single-payer National Health Insurance program since March 1, 1995, and approximately $98 \%$ of the total population (more than 23 million) is enrolled in this system. We used a subset of the NHIRD in this study, that is, the Psychiatric Inpatient Medical Claims (PIMC) database, which consists the information of all patients hospitalized for any psychiatric disorder between 1996 and 2012 ( $n=262879)$ (Figure 1). Patients with at least one psychiatric hospitalization record and one discharge diagnosis of mental illness with International Classification of Diseases, Ninth Revision (ICD-9) codes 290-319 between 1996 and 2012 were included in this PIMC database. The database comprises information regarding demographic characteristics, diagnoses, medical expenditures, and prescription claims for each patient.

From the PIMC database, we first enrolled patients who ever received the home care CM intervention between January 1, 1999, and December 31, 2010.[15] The date of patients when they first received home care CM was defined as the baseline. To ensure the accuracy of prior background information, we included those with at least one clinical visit before the 2-year period from the baseline ( $n=10276)$. After excluding 21 patients with missing information (eg, sex or the date of the visit), the final cohort ( $n=10255)$ for this study was identified.

The requirement of informed consent was waived because patients' information was encrypted before the analysis. All investigators signed an agreement guaranteeing patient confidentiality before using the database, and the Research Ethics Committee of Taipei City Hospital approved this study.

[Insert Figure 1 about here]

Mortality status and variables

The PIMC database provides information regarding mortality, and the registration of deceased patients is cancelled from the health insurance system. Thus, we could track the mortality status of each study patient from the PIMC database. The study framework is listed in e-Figure 1 (the supplement).

We collected patients' demographical and clinical information, namely age, sex, urbanization of the living area, employment status, major psychiatric diagnosis, Charlson comorbidity score, and physical illnesses, when they received the home care $\mathrm{CM}$ intervention for the first time. We used stratification for urbanization[18] specifically for Taiwan. The urbanization level was stratified as level 1 (highly urbanized area), level 2 (moderately urbanized area), level 3 (newly urbanized area), level 4 (township area), and level 5 (rural area). In addition, the Charlson comorbidity score $[19,20]$ was calculated to determine the severity of physical comorbidities. The Charlson comorbidity score is the sum of the weighted scores of 31 comorbid conditions and is widely used to assess the general health status in epidemiological surveys $[19,20]$.

Patient and public involvement

Patients are not involved in the design and conduct of the studies.

Statistical analysis 
In this study, we calculated contributed person-years for each patient from the baseline (when patients underwent home care $\mathrm{CM}$ for the first time during the study period) to the censor period; that is, mortality or the end of the study (December 31, 2012). The crude mortality rate for total causes of death was computed as incident cases divided by contributed person-years. Differences in the incidence of death between men and women were estimated using Gehan's generalized Wilcoxon test[21] and life-table survival analysis (e-Table 1 in the supplement).

We then calculated the SMR as the ratio of observed deaths in the study cohort to expected deaths in the general population of Taiwan [22]. More specially, we calculated the expected number of deaths (the denominator) based on 10-year age bands, by multiplying the average sex-specific mortality rate of the general population of Taiwan in the corresponding year and the contributed person-years of cohort patients during the at-risk period by each age and sex category, and then summed all values in each age and sex category as the total number of expected deaths.

Regarding potential risk factors for mortality, we first conducted the univariate Cox proportional hazards regression analysis to estimate the crude hazard ratios of variables including demographic factors and clinical characteristics. Based on the strategy of backward stepwise variable selection, we further performed multivariate regression to assess independent risk factors. Variables with a significant association $(P<.05)$ were retained in the final model. A P value of.05 was considered significant for interpretation. Statistical analyses were performed using SAS software, version 9.4 (SAS Institute Inc., Cary, NC, USA).

\section{Results}

Standardized mortality ratio (SMR)

Of 10255 patients who received home care CM, 1409 died during the study period (until December 31, 2012). The overall SMR was 3.13. After adjustment for sex, young patients (aged < 30 years) were found to have the highest SMR (10.97), and the SMR tended to decrease with an increase in age (Table 1).

Regarding the major psychiatric diagnosis, after adjustment for sex and age, patients with organic mental disorder were found to have an approximately 5 -fold risk of mortality compared with the general population $(S M R=4.98)$, patients with schizophrenia (SMR = 3.89), patients with major depression $(S M R=2.98)$, and patients with bipolar disorder $(S M R=1.97)$. Patients with dementia had a near 2-fold risk for mortality compared with the general population $(\mathrm{SMR}=1.88)$.

[Insert Table 1 about here]

As shown in e-Table 1 (listed in the supplement), the incidence of mortality in the study cohort clearly increased with age. Patients with dementia had the highest incidence of mortality, followed by those with organic mental disorder, major depression, bipolar disorder, and schizophrenia. Patients with dementia had the highest incidence of mortality, which could be due to the aging effect.

Demographics for mortality 
Table 2 shows the distribution of demographics and the findings of univariate analysis for the risk of mortality based on Cox proportional hazards regression. In the cohort, most patients were aged from 30 to 49 years and a substantial proportion of patients $(13.7 \%, 1409 / 10255)$ died during the follow-up period. The average contributed person-years for the entire cohort and deceased patients were 7.5 and 4.5 , respectively. More than half of deceased patients were men (56.1\%); however, we did not observe a significant sex difference in the risk of mortality. The risk of mortality tended to significantly increase with age. In addition, most institutions providing home care $\mathrm{CM}$ were located in urbanized areas. More than two-thirds $(69.3 \%)$ of patients were unemployed. The findings of the univariate analysis suggested an association of employment with a lower risk of mortality (hazard ratio $=0.79$ ).

[Insert Table 2 about here]

Clinical characteristics for mortality

Table 3 shows the distribution of psychiatric and physical illnesses. A substantial proportion of patients had schizophrenia (73.4\%) as the major psychiatric illness, followed by bipolar disorder, major depression, organic mental disorder, and dementia. Among these psychiatric illnesses, patients with dementia had the highest risk of mortality, followed by those with organic mental disorder. Patients who died had a higher Charlson comorbidity score than did the cohort. In addition, patients who died had a higher proportion of various comorbid acute or chronic physical illnesses.

[Insert Table 3 about here]

Multivariate analysis of risk factors for mortality

The results of the multivariate analysis showed that several variables remained significant in the final model (Table 4). The mortality risk increased significantly with age. In terms of psychiatric illnesses, patients with dementia had the highest risk of mortality (adjusted hazard ratio $=2.36$ ), followed by those with organic mental disorder (adjusted hazard ratio $=2.29$ ). The risk of mortality in patients with schizophrenia was comparable to that in patients with bipolar disorder or major depression. Among specified individual physical illnesses, cancer was the major risk factor for mortality (adjusted hazard ratio $=2.62$ ), followed by chronic hepatic disease (adjusted hazard ratio $=1.76$ ) and pneumonia (adjusted hazard ratio $=1.62$ ).

[Insert Table 4 about here]

\section{Discussion}

Major findings

In the present study, we investigated the mortality outcome and risk factors for mortality in Asian patients with SMDs who received home care $\mathrm{CM}$. Our findings implied that a substantial proportion of patients who received home care $\mathrm{CM}$ died during the study period because they were a high-risk population, and their overall SMR was 3.13. More specifically, the SMR of patients with schizophrenia and bipolar disorder who received home care $\mathrm{CM}$ was 3.89 and 1.97 , respectively. 
As meta-analysis reported no significant difference in the outcome of all-cause mortality rate or suicide mortality rate between the ICM and non-ICM intervention [16], the present study may be the first to report the SMR of patients with SMDs receiving a well-prescribed, non-ICM outreach intervention. To the best of our knowledge, no target population of study has reported findings comparable to those observed in our study; only one study[23] reported that patients who received randomized intensive outreach CM and were discharged from an inpatient psychiatry service at an urban general hospital in New York had an SMR of 2.25.

A recent study conducted in Taiwan[10] reported that the SMR of the total schizophrenia population for a 3year observation period was 3.40 and 3.14 for 2003 and 2008 cohorts, respectively, and the SMR of the bipolar population was 2.53 and 2.65 for 2003 and 2008 cohorts, respectively. Therefore, in Taiwan, patients with schizophrenia receiving home care $\mathrm{CM}$ may still have a higher mortality gap compared with those not receiving home care CM. By contrast, patients with bipolar disorder receiving the CM intervention may have lower mortality than those not receiving the $\mathrm{CM}$ intervention. Moreover, there are limited data for the comparison of other SMDs in the current literature.

In this study, as expected, older patients had a higher risk of mortality according to the findings of the multivariate analysis. By contrast, young patients (aged < 30 years) had the highest SMR (10.97), and the SMR tended to decrease with an increase in age. This phenomenon of the modification of the mortality risk based on age must be considered while calculating SMRs. This difference in the mortality risk can be because compared with the younger general population, younger individuals receiving home care CM had a wider health gap and deserve to be paid more attention for providing effective care.

Impact of major psychiatric illnesses on the mortality rate

In this study, considering patients with schizophrenia as the reference in the multivariate analysis, patients with organic mental disorder or dementia were found to have the highest risk of mortality after adjustment for confounding factors. The mortality risk of patients with schizophrenia was comparable to that of patients with bipolar disorder or major depression.

Our findings may be reasonable because schizophrenia, bipolar disorder, and major depression are considered as "major psychiatric disorders," whereas organic mental disorder and dementia are likely to inherently have the "organic basis" and could result in more physical comorbidities, which can contribute to a high mortality risk. For example, previous studies $[24,25]$ have reported that patients with organic mental disorder of all ages were at a risk for early death; in addition, the risk of early death was particularly high in patients during their early course, patients with cancer, female patients with heart disease, and male patients with influenza or pneumonia [26]. Future studies should determine the causes of death in this population in order to understand reasons underlying the high mortality risk and accordingly develop further care plan.

Physical illnesses as risk factors for mortality

In this study, patients with a higher Charlson comorbidity score had a higher risk of mortality. Regarding physical illnesses in the multivariate analysis, cancer as an individual physical illness was the major risk factor for mortality (adjusted hazard ratio $=2.62$ ), followed by chronic hepatic disease (adjusted hazard ratio $=1.76$ ) and pneumonia (adjusted hazard ratio $=1.62$ ). 
Patients with schizophrenia were reported to have a lower risk of cancer than did the general population [27]. However, a recent study[28] indicated that compared with the general population, patients with schizophrenia were more vulnerable to certain types of cancers, such as colorectal cancer and breast cancer, which are related to metabolic syndrome. Thus, the prevention and treatment of metabolic syndrome must be included in the care plan for these specified populations.

In this study, we found that hepatic disease and pneumonia were risk factors for mortality. Unhealthy lifestyle habits (such as smoking and alcohol use) and metabolic syndrome are related to the development of hepatic disease or pneumonia, which subsequently increase the risk of mortality [28, 29]. In addition, chronic liver disease was reported to be a common disease in patients with mental disorders [30]. Such untreated or undiagnosed comorbidity was associated with a more severe course of mental illness, decreased quality of life, and premature mortality [31]. Our findings regarding pneumonia are consistent with those of prior studies that reported patients with schizophrenia or bipolar disorder to have an increased risk of pneumonia [32-34], especially those using certain benzodiazepines or second-generation antipsychotics (such as clozapine) [35, 36].

The likelihood of death in patients with SMDs contribute to a major part of preventable physical diseases in their long-term course and to a less part of unnatural causes of death, including suicide, homicide, and accidents $[6,7,37,38]$. In our previous study [15], we reported that home care CM had a significant effect on reducing the frequency of psychiatric and involuntary admissions but not of physical medical utilization, such as nonpsychiatric admissions. The findings of this study provide evidence for alerting clinical staff to pay attention to physical illnesses that act as risk factors for mortality while caring for such patients.

\section{Limitation}

To the best of our knowledge, the present population-based cohort study based on a national registration database is the first to evaluate the mortality gap in patients with SMDs receiving home care CM. However, this study has several limitations that should be discussed. First, we did not have information regarding the causes of death; therefore, we could not examine the cause or underlying disease accounting for higher mortality. Second, the PIMC database includes the information of a hospital admission-based cohort; thus, study subjects included in the cohort were more severely ill. This might overestimate premature mortality in those with SMDs. Third, the SMR and incidence of mortality were used to measure the mortality outcome in the specified population, additional studies such as a randomized clinical trial are required to investigate whether the home care $\mathrm{CM}$ intervention can reduce mortality.

Implications

This study provides a more comprehensive picture of mortality gap in patients receiving home care $\mathrm{CM}$. The findings of this study highlight the need for more effective strategies to improve medical care, especially for patients with organic mental disorder. The intervention model integrated into the health care system for physical illnesses in this specified population deserves greater attention by health care policymakers, service providers, and clinicians.

\section{Declarations}


Contributors: WYC and CJK led the conception and design of the study. WYC and CJK wrote and revised the manuscript. WYC and CJK were responsible for the field investigation. WYC, CKC, and CHP participated in the data interpretation. SJH and TWY provided administrative and material support. WYC, CHP, and CJK reviewed and edited the manuscript. All authors approved the final version of the submitted manuscript.

Funding: This research was supported by grants from the Ministry of Science and Technology, Taiwan (MOST 105-2314-B-532-006-MY3) and Taipei City Hospital, Taiwan (TCDOH 10701-62-023). The funders had no role in study design, data collection, analysis, decision to publish, or preparation of the manuscript.

Competing interests: None declared.

Patient consent for publication: None required.

Ethics approval: This study was approved by the Research Ethics Committee of Taipei City Hospital, Taipei, Taiwan (ID: TCHIRB-10608111-E).

Provenance and peer review: Not commissioned; externally peer reviewed

Data sharing statement: No additional data available.

Acknowledgments: The authors thank Yin-Chi Chen, BS, of the Department of General Psychiatry, Taipei City Psychiatric Center, Taipei City Hospital, for data management and help with statistical analyses. This manuscript was edited by Wallace Academic Editing.

\section{References}

1.Patel V, Chisholm D, Parikh R, Charlson FJ, Degenhardt L, Dua T, Ferrari AJ, Hyman S, Laxminarayan R, Levin $C$ et al: Addressing the burden of mental, neurological, and substance use disorders: key messages from Disease Control Priorities, 3rd edition. Lancet 2016, 387(10028):1672-1685.

2.Chesney E, Goodwin GM, Fazel S: Risks of all-cause and suicide mortality in mental disorders: a meta-review. World Psychiatry 2014, 13(2):153-160.

3.Hoang U, Goldacre MJ, Stewart R: Avoidable mortality in people with schizophrenia or bipolar disorder in England. Acta Psychiatr Scand 2013, 127(3):195-201.

4.Amaddeo F, Bisoffi G, Bonizzato P, Micciolo R, Tansella M: Mortality among patients with psychiatric illness. A ten-year case register study in an area with a community-based system of care. Br J Psychiatry 1995, 166(6):783-788.

5.Harris EC, Barraclough B: Excess mortality of mental disorder. Br J Psychiatry 1998, 173:11-53.

6.Liu NH, Daumit GL, Dua T, Aquila R, Charlson F, Cuijpers P, Druss B, Dudek K, Freeman M, Fujii C et al: Excess mortality in persons with severe mental disorders: a multilevel intervention framework and priorities for clinical practice, policy and research agendas. World Psychiatry 2017, 16(1):30-40. 
7.John A, McGregor J, Jones I, Lee SC, Walters JTR, Owen MJ, O’Donovan M, DelPozo-Banos M, Berridge D, Lloyd K: Premature mortality among people with severe mental illness - New evidence from linked primary care data. Schizophr Res 2018.

8.Laursen TM, Nordentoft M, Mortensen PB: Excess early mortality in schizophrenia. Annu Rev Clin Psychol 2014, 10:425-448.

9.Talaslahti T, Alanen HM, Hakko H, Isohanni M, Hakkinen U, Leinonen E: Mortality and causes of death in older patients with schizophrenia. Int J Geriatr Psychiatry 2012, 27(11):1131-1137.

10.Pan YJ, Yeh LL, Chan HY, Chang CK: Transformation of excess mortality in people with schizophrenia and bipolar disorder in Taiwan. Psychol Med 2017, 47(14):2483-2493.

11.Kim W, Jang SY, Chun SY, Lee TH, Han KT, Park EC: Mortality in Schizophrenia and Other Psychoses: Data from the South Korea National Health Insurance Cohort, 2002-2013. J Korean Med Sci 2017, 32(5):835-842.

12.Fekadu A, Medhin G, Kebede D, Alem A, Cleare AJ, Prince M, Hanlon C, Shibre T: Excess mortality in severe mental illness: 10-year population-based cohort study in rural Ethiopia. Br J Psychiatry 2015, 206(4):289-296.

13.Saha S, Chant D, McGrath J: A systematic review of mortality in schizophrenia: is the differential mortality gap worsening over time? Arch Gen Psychiatry 2007, 64(10):1123-1131.

14.Staudt Hansen P, Frahm Laursen M, Grontved S, Puggard Vogt Straszek S, Licht RW, Nielsen RE: Increasing mortality gap for patients diagnosed with bipolar disorder-A nationwide study with 20 years of follow-up. Bipolar Disord 2018.

15.Chen WY, Hung YN, Huang SJ, Pan CH, Su SS, Yang TW, Kuo CJ: Nationwide analysis of medical utilization in people with severe mental illness receiving home care case management. Schizophr Res 2019, 208:60-66.

16.Dieterich M, Irving CB, Bergman H, Khokhar MA, Park B, Marshall M: Intensive case management for severe mental illness. Cochrane Database Syst Rev 2017, 1:Cd007906.

17.Coles BA: Intensive Case Management for Severe Mental IIIness. Issues Ment Health Nurs 2017:1-3.

18.Liu CY, Hung,Y. T.,Chuang,Y. L., Chen,Y. J., Weng, W. S., Liu, J. S., Liang, K. Y.: Incorporating development stratification of Taiwan townships into sampling design of large scale health interview survey. Journal of Health Management (Chinese) 2006, 4(1):1-22.

19.Quail JM, Lix LM, Osman BA, Teare GF: Comparing comorbidity measures for predicting mortality and hospitalization in three population-based cohorts. BMC Health Serv Res 2011, 11:146.

20.Quan H, Sundararajan V, Halfon P, Fong A, Burnand B, Luthi JC, Saunders LD, Beck CA, Feasby TE, Ghali WA: Coding algorithms for defining comorbidities in ICD-9-CM and ICD-10 administrative data. Med Care 2005, 43(11):1130-1139.

21.Lee ET: Statistical methods for survival data analysis. New York: John Wiley and Sons; 1992. 
22.Breslow NE, Day NE: Statistical methods in cancer research. Volume II-The design and analysis of cohort studies. IARC Sci Pub/1987(82):1-406.

23.Curtis JL, Millman EJ, Struening E, D’Ercole A: Deaths among former psychiatric inpatients in an outreach case management program. Psychiatr Serv 1996, 47(4):398-402.

24.Rossler W, Hewer W, Fatkenheuer B, Loffler W: Excess mortality among elderly psychiatric in-patients with organic mental disorder. Br J Psychiatry 1995, 167(4):527-532.

25.Black DW, Warrack G, Winokur G: The lowa record-linkage study. I. Suicides and accidental deaths among psychiatric patients. Arch Gen Psychiatry 1985, 42(1):71-75.

26.Black DW, Warrack G, Winokur G: The lowa record-linkage study. II. Excess mortality among patients with organic mental disorders. Arch Gen Psychiatry 1985, 42(1):78-81.

27.Goldacre MJ, Kurina LM, Wotton CJ, Yeates D, Seagroat V: Schizophrenia and cancer: an epidemiological study. Br J Psychiatry 2005, 187:334-338.

28.Chen LY, Hung YN, Chen YY, Yang SY, Pan CH, Chen CC, Kuo CJ: Cancer incidence in young and middle-aged people with schizophrenia: nationwide cohort study in Taiwan, 2000-2010. Epidemiol Psychiatr Sci 2018, 27(2):146-156.

29.John AP, Koloth R, Dragovic M, Lim SC: Prevalence of metabolic syndrome among Australians with severe mental illness. Med J Aust 2009, 190(4):176-179.

30.Patel K, Maguire E, Chartier M, Akpan I, Rogal S: Integrating Care for Patients With Chronic Liver Disease and Mental Health and Substance Use Disorders. Fed Pract 2018, 35(Suppl 2):S14-s23.

31.Fagiolini A, Goracci A: The effects of undertreated chronic medical illnesses in patients with severe mental disorders. J Clin Psychiatry 2009, 70 Supp/ 3:22-29.

32.Seminog 00, Goldacre MJ: Risk of pneumonia and pneumococcal disease in people with severe mental illness: English record linkage studies. Thorax 2013, 68(2):171-176.

33.Schoepf D, Uppal H, Potluri R, Heun R: Physical comorbidity and its relevance on mortality in schizophrenia: a naturalistic 12-year follow-up in general hospital admissions. Eur Arch Psychiatry Clin Neurosci 2014, 264(1):3-28.

34.Partti K, Vasankari T, Kanervisto M, Perala J, Saarni SI, Jousilahti P, Lonnqvist J, Suvisaari J: Lung function and respiratory diseases in people with psychosis: population-based study. Br J Psychiatry 2015, 207(1):3745.

35.Kuo CJ, Yang SY, Liao YT, Chen WJ, Lee WC, Shau WY, Chang YT, Tsai SY, Chen CC: Second-generation antipsychotic medications and risk of pneumonia in schizophrenia. Schizophr Bull 2013, 39(3):648-657.

36.Yang SY, Liao YT, Liu HC, Chen WJ, Chen CC, Kuo CJ: Antipsychotic drugs, mood stabilizers, and risk of pneumonia in bipolar disorder: a nationwide case-control study. J Clin Psychiatry 2013, 74(1):e79-86. 
37.OIfson M, Gerhard T, Huang C, Crystal S, Stroup TS: Premature Mortality Among Adults With Schizophrenia in the United States. JAMA Psychiatry 2015, 72(12):1172-1181.

38.Kredentser MS, Martens PJ, Chochinov HM, Prior HJ: Cause and rate of death in people with schizophrenia across the lifespan: a population-based study in Manitoba, Canada. J Clin Psychiatry 2014, 75(2):154-161.

\section{Tables}

Table 1. Standardized mortality ratios for all-cause mortality among patients who received home care case management, stratified by sex, age, and major psychiatric diagnosis in Taiwan, 1999-2010 ( $\mathrm{n}=10$ 255)

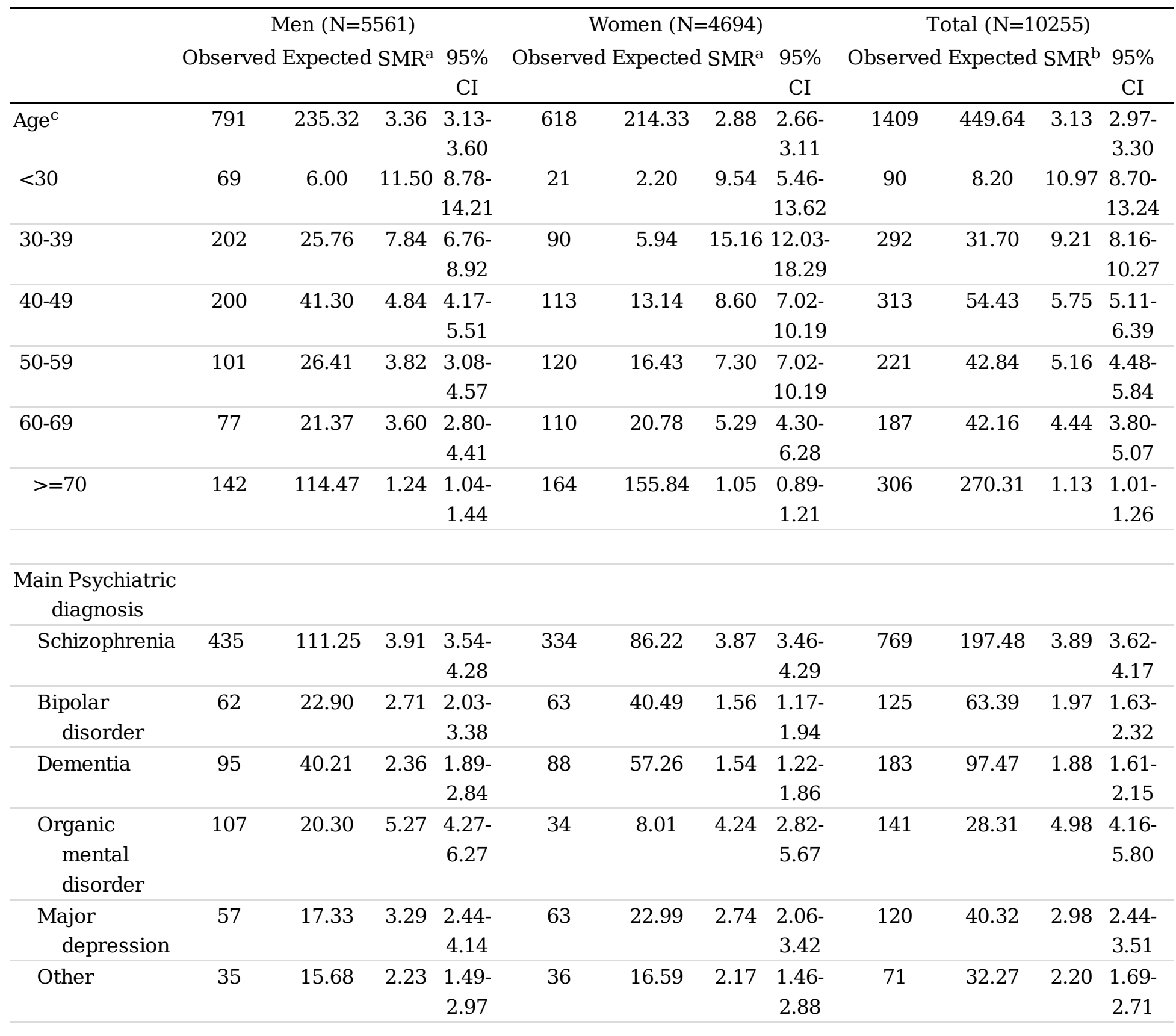

a: age-adjusted; b: sex-adjusted; c: age- and sex-adjusted

ICD-9 codes for dementia: 290, 294.1; ICD-9 codes for organic mental disorder: 294, except 294.1 
Table 2. Univariate regression based on the Cox proportional hazards model of demographical variables for the risk of mortality among patients who received the intervention of home care case management initially (the baseline) 


\begin{tabular}{|c|c|c|c|c|c|}
\hline & Cohort & Mortality & & & \\
\hline Characteristics & $\mathrm{N}=10255$ & $\mathrm{n}=1409$ & & & \\
\hline & $n(\%)$ & $n(\%)$ & $\begin{array}{c}\text { Unadjusted hazard } \\
\text { ratio }\end{array}$ & $\begin{array}{c}\text { 95\% confidence } \\
\text { interval }\end{array}$ & $\begin{array}{c}P \\
\text { value }\end{array}$ \\
\hline \multicolumn{6}{|l|}{ Gender } \\
\hline Male & $\begin{array}{c}5561 \\
(54.2)\end{array}$ & $791(56.1)$ & reference & & \\
\hline Female & $\begin{array}{c}4694 \\
(45.8)\end{array}$ & $618(43.9)$ & 0.94 & $0.84-1.04$ & 0.211 \\
\hline \multicolumn{6}{|l|}{ Age } \\
\hline$<30$ & $\begin{array}{c}1674 \\
(16.3)\end{array}$ & $90(6.4)$ & reference & & \\
\hline $30-39$ & $\begin{array}{c}3140 \\
(30.6)\end{array}$ & $292(20.7)$ & 1.90 & $1.50-2.40$ & $<.001$ \\
\hline $40-49$ & $\begin{array}{c}2810 \\
(27.4)\end{array}$ & $313(22.2)$ & 2.54 & $2.01-3.21$ & $<.001$ \\
\hline $50-59$ & $\begin{array}{c}1432 \\
(14.0)\end{array}$ & $221(15.7)$ & 4.07 & $3.18-5.20$ & $<.001$ \\
\hline $60-69$ & $640(6.2)$ & 187 (13.3) & 7.64 & $5.94-9.84$ & $<.001$ \\
\hline$>=70$ & 559 (5.5) & $306(21.7)$ & 19.11 & $15.09-24.21$ & $<.001$ \\
\hline \multicolumn{6}{|l|}{ Urbanization } \\
\hline 1 & $\begin{array}{c}3782 \\
(36.9)\end{array}$ & $603(42.8)$ & reference & & \\
\hline 2 & $\begin{array}{c}2023 \\
(19.7)\end{array}$ & $208(14.8)$ & 0.63 & $0.54-0.74$ & $<.001$ \\
\hline 3 & $\begin{array}{c}1135 \\
(11.1)\end{array}$ & 105 (7.5) & 0.69 & $0.56-0.85$ & $<.001$ \\
\hline 4 & $\begin{array}{c}2204 \\
(21.5)\end{array}$ & $340(24.1)$ & 0.92 & $0.81-1.06$ & 0.215 \\
\hline 5 & $\begin{array}{c}1111 \\
(10.8)\end{array}$ & $153(10.9)$ & 0.88 & $0.74-1.05$ & 0.151 \\
\hline \multicolumn{6}{|l|}{ Employment } \\
\hline No & $\begin{array}{c}7104 \\
(69.3)\end{array}$ & $\begin{array}{l}1020 \\
(72.4)\end{array}$ & reference & & \\
\hline \multirow[t]{2}{*}{ Yes } & $\begin{array}{l}3151 \\
(30.7)\end{array}$ & $389(27.6)$ & 0.79 & 0.71-0.89 & $<.001$ \\
\hline & $\begin{array}{c}\text { Mean } \\
(S D)\end{array}$ & $\begin{array}{c}\text { Mean } \\
(S D)\end{array}$ & & & \\
\hline Total contributed person-years & 77315.1 & 6345.4 & & & \\
\hline $\begin{array}{l}\text { Average contributed person-years, } \\
\text { SD }\end{array}$ & $7.5(3.6)$ & $4.5(3.2)$ & & & \\
\hline
\end{tabular}

We applied urbanization stratification specifically used in Taiwan, and the level of urbanization was categorized as level 1 (highly urbanized area), level 2 (moderately urbanized area), level 3 (township area), level 4 (sub-rural area), and level 5 (rural area). 
Table 3. Univariate analysis based on the Cox proportional hazards model of psychiatric and physical illnesses for the risk of mortality among patients who received the intervention of intensive case management initially (the baseline) 


\begin{tabular}{|c|c|c|c|c|c|}
\hline & Cohort & Mortality & & & \\
\hline Characteristics & $\mathrm{N}=10255$ & $\mathrm{~N}=1409$ & & & \\
\hline & $n(\%)$ & $n(\%)$ & $\begin{array}{l}\text { Unadjusted } \\
\text { hazard ratio }\end{array}$ & $\begin{array}{l}\text { 95\% confidence } \\
\text { interval }\end{array}$ & $\begin{array}{c}P \\
\text { value }\end{array}$ \\
\hline \multicolumn{6}{|c|}{$\begin{array}{l}\text { Major psychiatric diagnosis at the home } \\
\text { care CM }\end{array}$} \\
\hline Schizophrenia & $\begin{array}{c}7531 \\
(73.4)\end{array}$ & $\begin{array}{c}769 \\
(54.6)\end{array}$ & reference & & \\
\hline Bipolar disorder & $854(8.3)$ & 125 (8.9) & 1.57 & $1.30-1.89$ & $<.001$ \\
\hline Dementia & $308(3.0)$ & $\begin{array}{c}183 \\
(13.0)\end{array}$ & 9.56 & $8.13-11.25$ & $<.001$ \\
\hline Organic mental disorder & $548(5.3)$ & $\begin{array}{c}141 \\
(10.0)\end{array}$ & 3.17 & $2.65-3.80$ & $<.001$ \\
\hline Major depression & $582(5.7)$ & $120(8.5)$ & 2.06 & $1.70-2.49$ & $<.001$ \\
\hline Others & $\begin{array}{c}432 \\
(14.0)\end{array}$ & $71(5.0)$ & 1.56 & $1.22-1.99$ & $<.001$ \\
\hline \multicolumn{6}{|c|}{$\begin{array}{l}\text { Physical illnesses within } 1 \text { year before } \\
\text { the intervention }\end{array}$} \\
\hline \multicolumn{6}{|l|}{ Charlson comorbidity scale } \\
\hline 0 & $\begin{array}{l}7400 \\
(72.2)\end{array}$ & $\begin{array}{c}658 \\
(46.7)\end{array}$ & reference & & \\
\hline 1 & $\begin{array}{c}1617 \\
(15.8)\end{array}$ & $\begin{array}{c}283 \\
(20.1)\end{array}$ & 2.03 & $1.77-2.33$ & $<.001$ \\
\hline 2 & $667(6.5)$ & $\begin{array}{c}182 \\
(12.9)\end{array}$ & 3.43 & $2.91-4.05$ & $<.001$ \\
\hline 3 & $314(3.1)$ & $136(9.7)$ & 6.04 & $5.02-7.26$ & $<.001$ \\
\hline$\geqq 4$ & $257(2.5)$ & $\begin{array}{c}150 \\
(10.7)\end{array}$ & 10.89 & $8.77-12.53$ & $<.001$ \\
\hline Cardiovascular disease & $\begin{array}{c}2137 \\
(20.8)\end{array}$ & $\begin{array}{c}540 \\
(38.3)\end{array}$ & 2.71 & $2.44-3.02$ & $<.001$ \\
\hline Diabetes mellitus & $941(9.2)$ & $\begin{array}{c}254 \\
(18.0)\end{array}$ & 2.65 & $2.31-3.03$ & $<.001$ \\
\hline Cerebrovascular disease & $258(2.5)$ & $104(7.4)$ & 3.89 & $3.18-4.75$ & $<.001$ \\
\hline Chronic hepatic disease & $780(7.6)$ & $\begin{array}{c}200 \\
(14.2)\end{array}$ & 2.18 & $1.88-2.53$ & $<.001$ \\
\hline Cancer & $150(1.5)$ & $77(5.5)$ & 5.38 & $4.28-6.77$ & $<.001$ \\
\hline Pneumonia & $\begin{array}{c}384 \\
(3.74)\end{array}$ & $\begin{array}{c}113 \\
(8.02)\end{array}$ & 2.91 & $2.40-3.53$ & $<.001$ \\
\hline Asthma & $322(3.1)$ & $92(6.5)$ & 2.37 & $1.92-2.93$ & $<.001$ \\
\hline Upper respiratory tract infection & $\begin{array}{c}1604 \\
(15.6)\end{array}$ & $\begin{array}{c}203 \\
(14.4)\end{array}$ & 0.90 & $0.78-1.04$ & 0.162 \\
\hline Delirium $^{+}$ & $26(0.3)$ & $15(1.1)$ & 7.61 & $4.57-12.66$ & $<.001$ \\
\hline
\end{tabular}

Pneumonia was defined as the primary or any-listed discharge diagnosis with ICD-9 codes 480-486 and 507 
${ }^{+}$Based on the ICD-9 code, including presenile dementia with delirium, senile dementia with delirium, arteriosclerotic dementia with delirium, alcohol withdrawal delirium, drug-induced delirium, acute delirium, and subacute delirium

Table 4. Multivariate analysis ${ }^{\mathrm{a}}$ of risk factors for mortality among patients who received home care case management $(\mathrm{n}=10255)$

\begin{tabular}{|c|c|c|c|c|c|}
\hline \multirow{3}{*}{ Characteristics } & Cohort & Mortality & & \multirow[b]{3}{*}{$95 \% C I$} & \multirow[b]{3}{*}{$\begin{array}{c}P \\
\text { value }\end{array}$} \\
\hline & $\mathrm{N}=10255$ & $\mathrm{n}=1409$ & & & \\
\hline & $N(\%)$ & $N(\%)$ & $\begin{array}{c}\text { Adjusted hazard } \\
\text { ratio }\end{array}$ & & \\
\hline \multicolumn{6}{|l|}{ Age } \\
\hline$<30$ & $\begin{array}{c}1674 \\
(16.3)\end{array}$ & $90(6.4)$ & reference & & \\
\hline $30-39$ & $\begin{array}{l}3140 \\
(30.6)\end{array}$ & $\begin{array}{c}292 \\
(20.7)\end{array}$ & 1.88 & $1.49-2.39$ & $<.001$ \\
\hline $40-49$ & $\begin{array}{l}2810 \\
(27.4)\end{array}$ & $\begin{array}{c}313 \\
(22.2)\end{array}$ & 2.42 & 1.92-3.07 & $<.001$ \\
\hline $50-59$ & $\begin{array}{c}1432 \\
(14.0)\end{array}$ & $\begin{array}{c}221 \\
(15.7)\end{array}$ & 3.65 & $2.85-4.67$ & $<.001$ \\
\hline $60-69$ & $640(6.2)$ & $\begin{array}{c}187 \\
(13.3)\end{array}$ & 6.28 & 4.87-8.11 & $<.001$ \\
\hline$<=70$ & $559(5.5)$ & $\begin{array}{c}306 \\
(21.7)\end{array}$ & 11.37 & $\begin{array}{l}8.77- \\
14.74\end{array}$ & $<.001$ \\
\hline \multicolumn{6}{|c|}{ Major psychiatric diagnosis at the home care $\mathrm{CM}$} \\
\hline Schizophrenia & $\begin{array}{c}7531 \\
(73.4)\end{array}$ & $\begin{array}{c}769 \\
(54.6)\end{array}$ & reference & & \\
\hline Bipolar disorder & $854(8.3)$ & $125(8.9)$ & 1.20 & $0.99-1.45$ & 0.066 \\
\hline Dementia & $308(3.0)$ & $\begin{array}{c}183 \\
(13.0)\end{array}$ & 2.36 & $1.93-2.89$ & $<.001$ \\
\hline Organic mental disorder & $548(5.3)$ & $\begin{array}{c}141 \\
(10.0)\end{array}$ & 2.29 & $1.90-2.75$ & $<.001$ \\
\hline Major depression & $582(5.7)$ & $120(8.5)$ & 1.18 & $0.96-1.44$ & 0.108 \\
\hline Others & $432(14.0)$ & $71(5.0)$ & 1.20 & $0.94-1.54$ & 0.146 \\
\hline \multicolumn{6}{|c|}{$\begin{array}{l}\text { Physical illnesses within } 1 \text { year before the } \\
\text { intervention }\end{array}$} \\
\hline Chronic hepatic disease & $780(7.6)$ & $\begin{array}{c}194 \\
(13.8)\end{array}$ & 1.76 & $1.51-2.05$ & $<.001$ \\
\hline Cancer & $150(1.5)$ & $72(5.1)$ & 2.62 & $2.07-3.32$ & $<.001$ \\
\hline Pneumonia & $384(3.74)$ & $\begin{array}{c}113 \\
(8.02)\end{array}$ & 1.62 & $1.33-1.98$ & $<.001$ \\
\hline
\end{tabular}




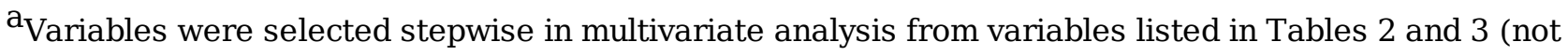
including the Charlson comorbidity scale). Variables with $P<.05$ were remained in the final model.

\section{Figures}

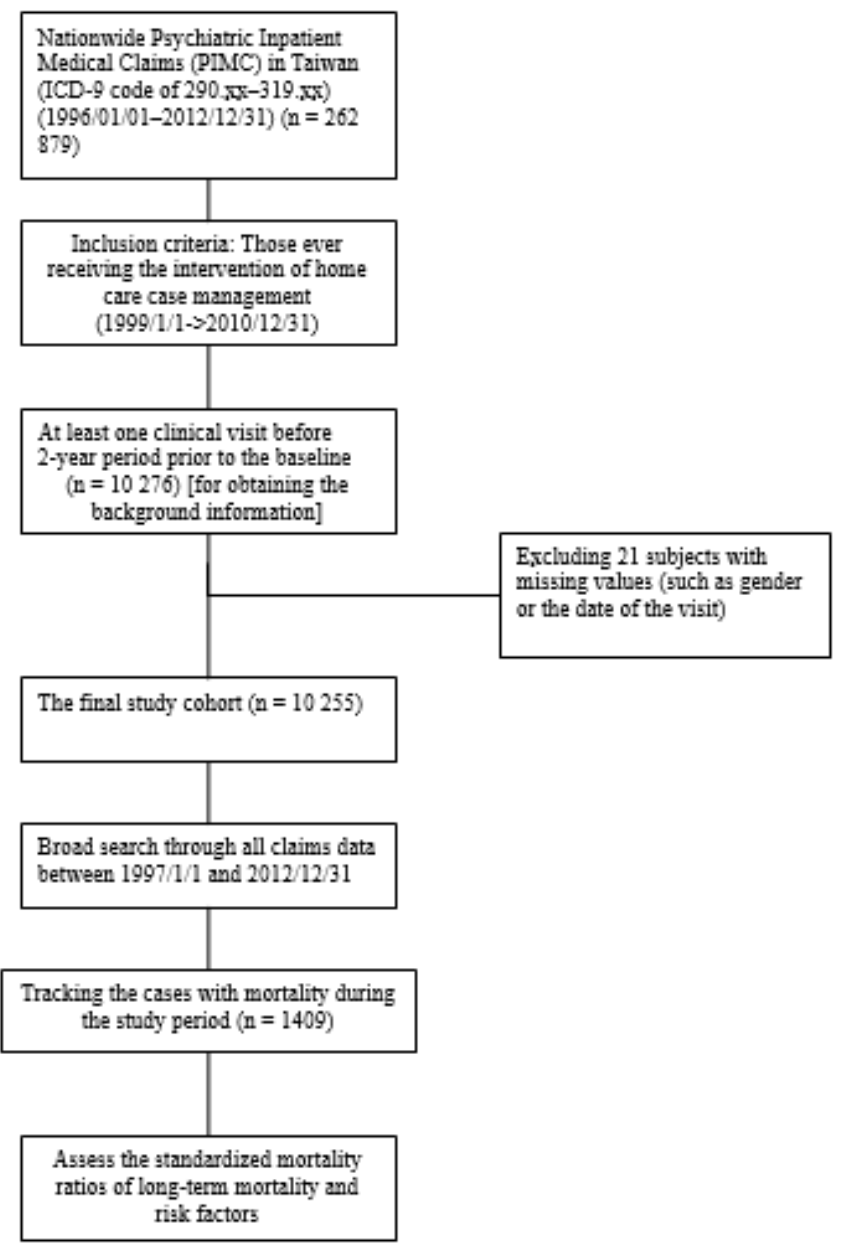

\section{Figure 1}

Study flow diagram (mortality in those receiving home care case management)

\section{Supplementary Files}

This is a list of supplementary files associated with this preprint. Click to download.

- B0724Supplement20191031.doc 